Book Power in Communication, Sociology and Technology

Ed. Angela Repanovici, Manolis Koukourakis, Tereza Khecyoyan

Series: Philosophy, Communication, Media Sciences

Available online at http://trivent-publishing.eu/

\title{
Representative Publications for Medical Engineering
}

\author{
Corneliu Druga \\ Department DPMM, Transilvania University of Brasov, \\ Romania,druga@unitbv.ro
}

\begin{abstract}
From the perspective of publications in the field of medical engineering, there is a great diversity which requires filtering in order to identify representative journals and papers. There are search engines which do not always provide the necessary filtering. In this direction, for example, Elsevier has a search engine in its own journals, which provides keyword filtering such as the title of the paper and the abstract. Following this search, one can obtain information on the representative journals by identifying some useful scientometrics data to disseminate one's own research.
\end{abstract}

Keywords: Biomedical; Biomaterials; CiteScore; IF; SNIP; SJR; h5-index; h5median; Eigenfactor.

DOI: 10.22618/TP.PCMS.20181.156014

This is an Open Access article distributed in accordance with the Creative Commons Attribution Non Commercial (CC-BY-NC-ND 4.0) license, which permits others to copy or share the article, provided original work is properly cited and that this is not done for commercial purposes. Users may not remix, transform, or build upon the material and may not distribute the modified material (http:/ / creativecommons.org/ licenses/by-nc/4.0/) 


\title{
Representative Publications for Medical Engineering
}

\author{
Corneliu Druga \\ Department DPMM, Transilvania University of Brasov, \\ Romania
}

\section{Introduction}

Biomedical Engineering is an interdisciplinary domain which links many disciplines such as engineering, medicine, biology, physics, electronic, science and technology of materials, etc. A good example in this direction is a paper written by our colleagues ${ }^{1}$. This rapidly growing field must meet the needs of industrial, clinical, and scientific research communities. It involves the application of state-of-the-art technology to the creation of methodologies and devices for human welfare and for better understanding of human biological processes ${ }^{2}$. The Biomedical Engineering curriculum at most universities and institutes typically comprises subjects like: Biomaterials, Biomechanics, Biosensors, Medical Imaging, Prosthetic Devices, Bioinformatics, Biotechnology, etc. (Fig. 1). In this case the students are exposed to both engineering and biology subjects. Nor are students in Medical Engineering, from the Faculty of Product Design and Environmental, an exception. It is very important that the medical field is so large as to be the list of representatives of this field. The purpose of this article is to identify a number of scientific parameters contributing to a classification of a journalist in the field of medical engineering. This is useful for all user groups from researchers to teachers working in this area. For this, a series of scintillation indicators such as: Cite Score, Impact Factor (IF), 5-year Impact Factor, SNIP, Scimago Journal Rank (SJR) and h5-index.

\footnotetext{
${ }^{1}$ I. Serban, I.C.Rosca, M. Baritz, "Influence of sound frequency on human body stability," Environmental Engineering and Management Journal 15 (2016): 375-381.

2 Somesh Menon, Careers360. https://medicine.careers360.com/articles/biomedical-engineeringfusion-of-two-domains (accessed October 20, 2017).
} 


\section{Biomechanics}

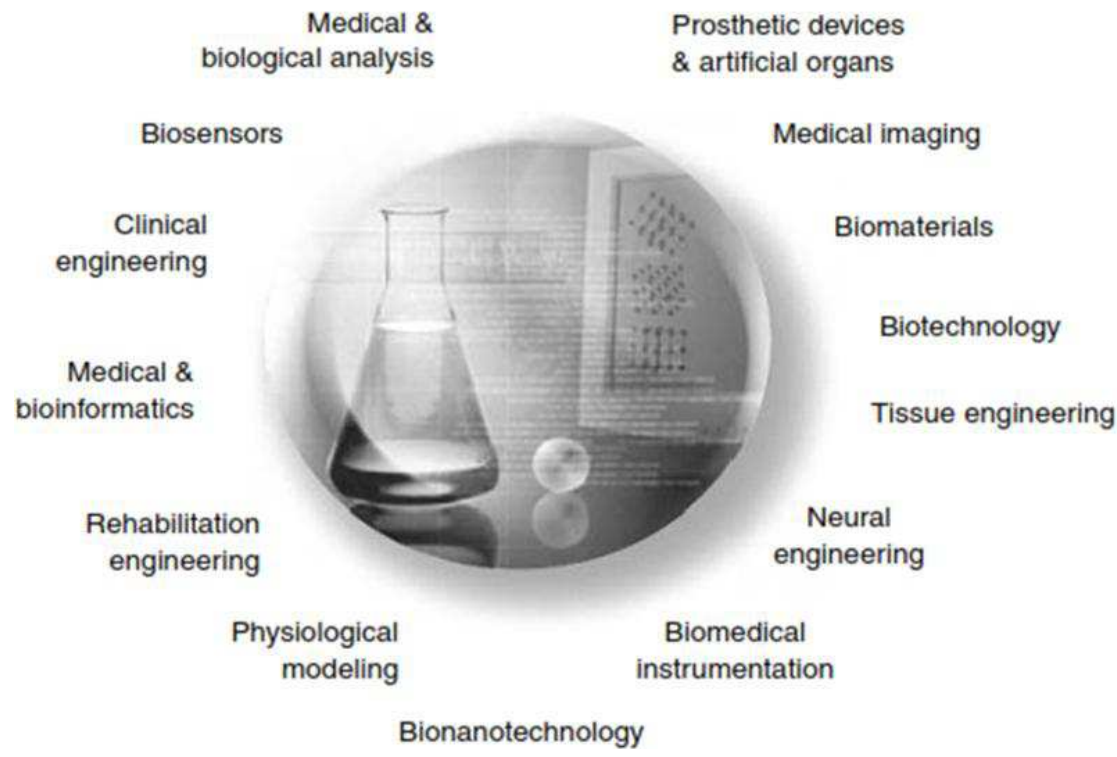

Fig. 1. The world of Biomedical Engineering ${ }^{3}$

\section{Bibliometric indicators of impact}

There are a number of bibliometric indicators focusing on measuring impact of scholarly journals. Most of these measures are calculated from the pool of journals indexed in three citation indexing databases: Web of Science, Scopus and Google Scholar.

\section{Web of Science indicators}

Web of Science's core indicators are: Impact Factor, Immediacy Index, Cited/citing half-life and Eigenfactor (Table 1). These indicators are described below:

- The impact factor (IF) or journal impact factor (JIF) is a measure reflecting the yearly average number of citations to recent articles published in that journal ${ }^{4}$. The impact factor (IF) is a measure of the frequency with which the average article in a journal has been cited in a particular year. It is used to measure the importance or rank of a journal by calculating the times its articles are cited.

- The Eigenfactor score, developed by Jevin West and Carl Bergstrom at the University of Washington, is a rating of the total importance of a scientific journal. Journals are rated according to the number of incoming citations, with citations from highly ranked journals weighted to make a larger contribution to the Eigenfactor than those from poorly ranked journals. ${ }^{5}$

- The Immediacy Index is the average number of times an article is cited in the year it is published. The journal Immediacy Index indicates how quickly articles in a journal are

\footnotetext{
3 Joseph Bronzino, ed. Medical Devices and Systems (New York: CRC Press Taylor \& Francisc Group, 2006), 10-12.

${ }^{4}$ Wikipedia. Impact factor. https://en.wikipedia.org/wiki/Impact_factor (accessed October 21, 2017).

${ }^{5}$ Wikipedia. Eigenfactor. https://en.wikipedia.org/wiki/Eigenfactor (accessed October 21, 2017).
} 
cited. The Immediacy Index is calculated by dividing the number of citations to articles published in a given year by the number of articles published in that year.

- Cited Half-Life refers to the median age of the citations received by a journal during the JCR year. A citation's age is equal to the publication year of the citing item minus the publication year of the cited item. ${ }^{6}$

Table 1. Bibliometric indicators of impact

\begin{tabular}{|l|l|l|}
\hline \multicolumn{3}{|c|}{ Based indicators } \\
\hline \multicolumn{1}{|c|}{ Web of Science } & \multicolumn{1}{|c|}{ SCOPUS } & \multicolumn{1}{|c|}{ Google Scholar } \\
\hline Impact Factor & SNIP & h5-index \\
Immediacy Index & SJR & h5-core \\
Cited/citing half-life & CiteScore & h5-meian \\
Eigenfactor & \\
\hline
\end{tabular}

\section{SCOPUS indicators}

Scopus's core indicators are: Source Normalized Impact per Paper (SNIP), SJR (SCImago Journal Rank) and CiteScore (Table 1). These indicators are described below:

- CiteScore is a simple way of measuring the citation impact of serial titles such as journals. CiteScore calculates the average number of citations received in a calendar year by all items published in that journal in the preceding three years.

- SNIP - a factor released in 2012 by Elsevier based on Scopus to estimate impact. The measure is calculated as $S N I P=R I P /(R / M)$, where RIP-raw impact per paper, $\mathrm{R}$ citation potential and $\mathrm{M}$ - median database citation potential.

- SJR indicator is a measure of scientific influence of scholarly journals that accounts for both the number of citations received by a journal and the importance or prestige of the journals where such citations come from. The SJR indicator is a free journal metric which uses an algorithm similar to PageRank and provides an alternative to the impact factor (IF) ${ }^{6}$. Scopus-based metrics can be accessed via SCOPUS platform as well as via JournalMetrics.com, CW'TS Journal Indicators and Scimago (SJR indicator only) websites.

\section{Google Scholar indicators}

Google Scholar Metrics is another source of journal-level metrics. Google Scholar's core indicators are: $\mathrm{h} 5$-index, h5-core and h5-median.These indicators are described below:

- The $\mathrm{h}$-index of a publication is the largest number $\mathrm{h}$ such that at least $\mathrm{h}$ articles in that publication were cited at least $\mathrm{h}$ times each. For example, a publication with five articles cited by, respectively, 17, 9, 6, 3, and 2, has the h-index of $3 .^{7}$

- The h-core of a publication is a set of top cited $h$ articles from the publication. These are the articles that the h-index is based on. For example, the publication above has the h-core with three articles, those cited by 17,9 , and 6 .

- The h-median of a publication is the median of the citation counts in its h-core. For example, the h-median of the publication above is 9 . The h-median is a measure of the distribution of citations to the articles in the h-core.

\footnotetext{
${ }^{6}$ https://clarivate.com/blog/a-closer-look-at-cited-and-citing-half-lives (accessed October 23, 2017).

7 https://scholar.google.com/intl/en/scholar/metrics.html\#metrics (accessed October 23, 2017).
} 
Finally, the h5-index, h5-core, and h5-median of a publication are, respectively, the hindex, h-core, and h-median of only those of its articles that were published in the last five complete calendar years articles. ${ }^{7}$

\section{Search engines}

Given that the Biomaterials sub-domain is present in all educational institutions active in the field of Medical Engineering, we considered that it would be necessary to identify the most representative journals in this field. This can be done in two ways: the journals are selected from a series of scientometric indicators such as those described above or from the article we want to publish.

Method I: I used the platform Scimago Journal \& Country Rank which provides us with a list of the most representative journals in terms of the SJR indicator.

The list of journals includes 66 titles where the SJR ranges from 4,915 to 0.121 for the year 2016. Users can search for other types of publications, such as: Book series, Trade journals or Conference and Proceedings, from 1999 until 2016. In addition, it is possible to set the geographic area where the publications can come from. As shown in this list, the Advanced Functional Materials Journal has the highest SJR (4.915). Advanced Functional Materials is known for its rapid and fair peer review, quality content, and high impact (2017 Journal Citation Reports: 12.12), making it the first choice of the international materials science community. To see what the impact factor is for the same log we can use the available platform at: Journal Impact Factor List www.scijournal.org (Fig.2). According to this platform, the Impact Factor for 2016 is 12.124. The Google Scholar platform-specific indexes, h5-index and h5-median, for this journal are 133 and 186 respectively. The Relative Influence Score (RIS) for the Advanced Functional Materials Journal for 2017 is $8,719$.

Method II: If we have an article and want to identify a journal where we can post the article for publication, we can call Elsevier Journal Finder, Springer Journal Finer or Wiley Journal Finder. For example, I used the title and abstract of an article written by a number of colleagues from Transylvania University in Brasov in the biomaterials domain in this year within the Elsevier Journal Finder platform. ${ }^{8}$

\footnotetext{
${ }^{8}$ R. Miclaus, A. Repanovici, N. Roman, "Biomaterials: Polylactic Acid and 3D Printing Processes for
} Orthosis and Prosthesis," Materiale Plastice 54 (2017): 98-102. 


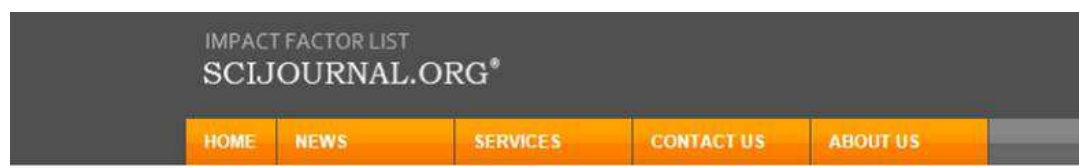

\section{Submit Paper $\quad$ ANCED FUNCTIONAL MATERIALS IMPACT FACTOR [Submission to All Listed Journals.]}

\section{SCIJOURNAL.ORG \\ SUBMIT JOURNAL}

\section{PublMed}

National
Library
of Medicine
Journal Abbreviation: ADV FUNCT MATER

Journal ISSN: 1616-301X

JOURNAL IMPACT FACTOR DETAILS

2016/2017 Impact Factor : 12.124

2015 Impact Factor : 11.382

2014 Impact Factor : 11.805

2013 impact Factor: 10.439

2012 Impact Factor : 9.765

Fig. 2. Journal Impact Factor List

\section{ELSEVIER}

\section{Search results (10)}

\section{Journal title Sort by Match $\downarrow$ Impact Factor CiteScore Open Access Review speed Acceptance Production speed}

Acta Biomaterialia

\begin{tabular}{|c|c|c|c|c|c|c|c|}
\hline 6.319 & 6.66 & 3 weeks & $22 \%$ & 8 weeks & Optional & 24 Months & S 3,000 More info $\square$ \\
\hline Impact & CiteScore & Review speed & Acceptance & Production speed & Open Access & Embargo period & OA Fee + License \\
\hline
\end{tabular}

Composites Part B: Engineering

More metrics details

\begin{tabular}{|c|c|c|c|c|c|c|c|c|}
\hline$=$ & 4.727 & 5.19 & 5 weeks & $29 \%$ & 5 weeks & Optional & 24 Months & \$ 2,500 More info $\square$ \\
\hline Match & Impact & CiteScore & Review speed & Acceptance & Production speed & Open Access & Embargo period & OA Fee + License \\
\hline
\end{tabular}

Polymer Testing

More metrics details

\begin{tabular}{|c|c|c|c|c|c|c|c|c|}
\hline$=$ & 2.464 & 2.82 & 5 weeks & $27 \%$ & 4 weeks & Optional & 24 Months & S 3,300 More info $\square$ \\
\hline Matc & Impact & CiteScore & Review speed & Acceptance & Production speed & Open Access & Embargo period & OA Fee + License \\
\hline
\end{tabular}

Fig. 3. The partial result of identifying journales using the Elsevier Journal Finder platform

Optionally, research fields can also be complemented, or open access journals can be filtered. Following the search, there were 10 suggestions of journals that show a series of information such as: Impact factor, CiteScore, Review speed, Acceptance rate or Production speed (Fig.3). The same information was also used in the Springer Journal Suggester platform, with the result of 20 journals that show a series of information such as: Impact Factor, Acceptance rate and Time to first decision (Fig.4). A real benefit to writers of less experienced articles in this direction is to find out where to publish a journal where the 
Enago Academy platform is presented, detailing the whole procedure, from the identification of the journal to how to write the article. ${ }^{\text {? }}$

1. Heritage Science

Fig. 4. The partial result of identifying journales using the Springer Journal Suggester platform

\section{Conclusions}

Since the methodologies for calculating the different indicators specific to the three platforms (Web of Science, Scopus and Google Scholar) are different, the criteria that we must consider when choosing a journal are: Impact Factor, CiteScore, Relative Influence Score, Review speed, Acceptance rate, Publishing fee and, last but not least, the indicators that are taken into account in the institution where you operate. At Transylvania University of Brasov, one of the promotion criteria is related to the publication of articles with RIS (Relative Influence Score) greater than 0.7. If there is an article, the simplest way to identify a journal is to use the Elsevier or Springer platforms described above. Acceptance rate and publication fee are also very important in choosing a journal. Generally speaking, it is preferable for young researchers to choose journals with lower Scientometric Indicators and a higher Acceptance rate.

\footnotetext{
${ }_{9}^{9}$ Enago Academy, Elsevier Journal Finder: How to Select an Appropriate Journal for Publishing, https://www.enago.com/academy/elsevier-journal-finder-select-appropriate-journal-publishing/ (accessed October 24, 2017).
} 


\section{References}

Serban, I., Rosca, I. C., Baritz, M. "Influence of sound frequency on human body stability." Environmental Engineering and Management Journal 15 (2016): 375-381.

Somesh, Menon. Careers360. https://medicine.careers360.com/articles/biomedicalengineering-fusion-of-two-domains (accessed October 20, 2017).

Bronzino, Joseph, ed. Medical Devices and Systems. New York: CRC Press Taylor \& Francisc Group, 2006.

Wikipedia. Impact factor. https://en.wikipedia.org/wiki/Impact_factor (accessed October 21, 2017).

Wikipedia. Eigenfactor. https://en.wikipedia.org/wiki/Eigenfactor (accessed October 21, 2017).

https://clarivate.com/blog/a-closer-look-at-cited-and-citing-half-lives (accessed October 23, 2017).

https://scholar.google.com/intl/en/scholar/metrics.html\#metrics (accessed October 23, 2017).

Miclaus, R., Repanovici, A., Roman, N. "Biomaterials: Polylactic Acid and 3D Printing Processes for Orthosis and Prosthesis", Materiale Plastice 54 (2017): 98-102.

Enago Academy. Elsevier Journal Finder: How to Select an Appropriate Journal for Publishing . https://www.enago.com/academy/elsevier-journal-finder-select-appropriate-journalpublishing/ (accessed October 24, 2017). 